\title{
Batalla de frames en la campaña electoral de abril de 2019. Engagement y promoción de mensajes de los partidos políticos en Facebook
}

\section{Battle of frames during the electoral campaign of April 2019: engagement and promotion of political parties' messages on Facebook}

\author{
Carlos A. Ballesteros-Herencia; Salvador Gómez-García
}

Cómo citar este artículo:

Ballesteros-Herencia, Carlos A.; Gómez-García, Salvador (2020). "Batalla de frames en la campaña electoral de abril de 2019. Engagement y promoción de mensajes de los partidos políticos en Facebook". Profesional de la información, v. 29, n. 6, e290629.

https://doi.org/10.3145/epi.2020.nov.29

Artículo recibido el 07-05-2020 Aceptación definitiva: 14-06-2020

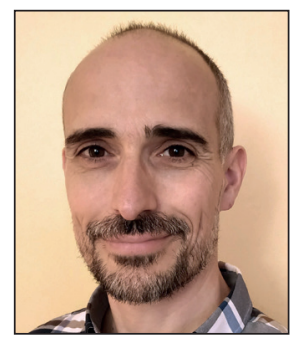

Carlos A. Ballesteros-Herencia https://orcid.org/0000-0002-8990-7949

Universidad de Valladolid Facultad de Filosofía y Letras Plaza del Campus, $\mathrm{s} / \mathrm{n}$. 47011 Valladolid, España cballesteros@hmca.uva.es $\bowtie$

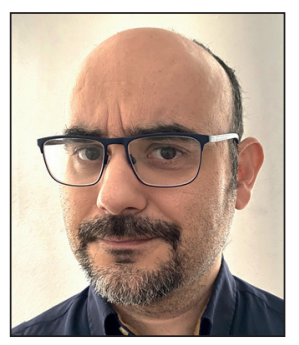

Salvador Gómez-García https://orcid.org/0000-0001-5126-6464

Universidad de Valladolid

Facultad de Filosofía y Letras

Plaza del Campus, s/n.

47011 Valladolid, España

salvadorgomez@hmca.uva.es

\section{Resumen}

Los procesos de enmarcado, encuadre o framing son uno de los objetos de estudio preferentes en el área de Comunicación, a pesar de las frecuentes y reputadas críticas sobre su solidez teórica y metodológica. En esta investigación se sigue la propuesta de Matthes y Kohring (2008) para la detección de frames mediante análisis estadístico de conglomerados que operacionaliza en elementos de enmarcado los componentes de la definición de Entman (1993). Se aplica al estudio de la campaña electoral que hicieron los principales partidos políticos españoles a través de Facebook en la convocatoria del 28 de abril de 2019. Se capturaron automatizadamente todos los mensajes publicados en esta red social en los quince días de campaña electoral, detectándose el uso de cuatro grandes frames por parte de los partidos: marco de eventos y cuestiones políticas, marco de petición de voto, marco del partido rival y marco del tratamiento mediático. Los partidos utilizaron en diferente medida estos marcos: desde la campaña institucional y en positivo del PSOE; a la campaña volcada en criticar al partido gobernante del principal partido de la oposición, el PP; pasando por la inclinación hacia el tratamiento mediático de Unidas Podemos, o a centrarse en sus propios actos y propuestas de Ciudadanos y Vox. Se detectó una correlación negativa entre los frames más empleados por las formaciones políticas en su conjunto y el nivel de engagement en Facebook, si bien la utilización concreta de los marcos por parte del PSOE y Unidas Podemos sí mostró cierto paralelismo con los niveles de interacción en esta red social.

\section{Palabras clave}

Marcos; Encuadres; Frames; Marcos partidistas; Redes sociales; Partidos políticos; Comunicación política; Campañas electorales; Campañas online; Cibercampañas; Compromiso; Fidelidad; Facebook; España. 


\begin{abstract}
Framing processes are one of the preferred objects of study in the area of Communication, despite the frequent criticism regarding their theoretical and methodological strength. This study follows the proposal of Matthes and Kohring (2008) of the detection of frames through statistical analysis of clusters that operationalize the components as defined by Entman (2003) using framing elements. This is applied to the study of the electoral campaign on Facebook of the main Spanish political parties in the election of 28 April 2019. All messages published on this social network during the 15 days of the electoral campaign were captured automatically. The use of four large frames by the parties was detected, corresponding to events and political questions, request for vote, the rival party, and media treatment. The parties used these frames to different degrees: from the institutional and positive campaign of the PSOE, to the campaign aimed at criticizing the ruling party of the main opposition party, the $P P$, through the inclination towards media treatment of Unidas Podemos, or a focus on their own events and proposals by Ciudadanos and Vox. A negative correlation was detected between the frames most used by the political formations as a whole and the level of user engagement on Facebook, although the use of frames by PSOE and Unidas Podemos showed a greater parallelism with the levels of interaction in this social network.
\end{abstract}

\title{
Keywords
}

Party frames; Advocacy frames; Framing; Frames; Social networks; Political parties; Political communication; Election campaigns; Online campaigns; Engagement; Facebook; Spain.

\section{Introducción}

La investigación del framing se enfrenta a una paradoja crucial: a pesar de ser considerada como una de las perspectivas más utilizadas en los estudios sobre Comunicación (Bryant; Miron, 2004; Weaver, 2007), y muy concretamente dentro de la política y las campañas electorales (Piñeiro-Naval; Mangana, 2019), abundan las críticas (Entman, 1993; De-Vreese, 2012) hacia una aplicación metodológicamente imprecisa de un concepto teórico exitoso, pero tan vago que permite incluso su simple consideración como "tratamiento informativo" de una cuestión. Autores como Matthes y Kohring (2008) han propuesto superar esta situación definiendo como variables los elementos de una determinada concepción de frame (en su caso la de Entman (1993) pero reconociendo la posibilidad de operar de forma similar con otras interpretaciones), y analizándolas estadísticamente.

Por otra parte, la investigación académica se ha centrado en los marcos mediáticos, generándose un desequilibrio en el estudio del resto del proceso de enmarcado, descrito por autores como Scheufele (1999) o D’Angelo (2002). A partir de las cuestiones anteriores, esta investigación aborda el estudio de los marcos propuestos por las fuentes originales de información, los marcos de los actores partidistas (party frames, advocacy frames) en el caso de las campañas electorales. Complementariamente, se estudia la articulación dentro de la Comunicación Política en redes sociales de un concepto, el framing, más prolíficamente estudiado hasta la fecha en medios tradicionales.

\subsection{Elecciones generales del 28 de abril de 2019}

El 28 de abril de 2019 se celebraron las decimocuartas elecciones generales en España desde el inicio de la transición democrática. El presidente del Gobierno, el socialista Pedro Sánchez, convocó elecciones el 15 de febrero de ese año, dos días después de que el Congreso de los Diputados hubiera rechazado su proyecto de presupuestos. Sánchez había llegado al Gobierno el 1 de junio de 2018 a través de una moción de censura contra el entonces presidente, Mariano Rajoy, vencedor con minoría simple en las elecciones de junio de 2016. Tras la moción, Rajoy renunció a su cargo al frente del Partido Popular (PP), siendo sustituido por Pablo Casado.

Los resultados electorales supusieron un vuelco en el tablero político español al convertirse el Partido Socialista Obrero Español (PSOE) en la fuerza más votada con seis puntos más que en 2016 , mientras los votos del $P P$ se redujeron a la mitad (del $33 \%$ al $16,7 \%$ ). Los dos partidos emergentes en 2015 mostraron tendencias opuestas, mientras la formación centrista Ciudadanos incrementó en casi tres puntos sus votos, a menos de un punto $(15,9 \%)$ del $P P$, la izquierdista Unidas Podemos experimentó un retroceso de casi siete puntos, quedándose en el $14,31 \%$. Pero la gran novedad fue la irrupción de la derecha nacionalista de Vox, que pasó del 0,2\% en 2015 al 10,26\% en 2019, obteniendo 24 diputados (ver datos en la tabla 1).
Tabla 1. Resultados en las elecciones generales 2011-2019

\begin{tabular}{|l|c|c|c|c|}
\hline \multicolumn{1}{|c|}{ Partido } & $\mathbf{2 0 1 9}$ & $\mathbf{2 0 1 6}$ & $\mathbf{2 0 1 5}$ & $\mathbf{2 0 1 1}$ \\
\hline PSOE & 28,67 & 22,63 & 22,01 & 28,76 \\
\hline$P P$ & 16,69 & 33,01 & 28,71 & 44,63 \\
\hline CS & 15,86 & 13,06 & 13,94 & - \\
\hline Unidas Podemos * & 14,31 & 21,10 & 24,33 & 7,81 \\
\hline Vox & 10,26 & 0,20 & 0,23 & - \\
\hline
\end{tabular}

Nota: datos en porcentaje. *2015 Suma de Podemos, IU y Equo. 2011 Suma de IU y Equo. Podemos no se presentó. Fuente: Ministerio del Interior (2019).

\subsection{Redes sociales en campaña electoral}

El carácter crucial de los períodos electorales para los tres componentes clásicos de la comunicación política: partidos, ciudadanos y medios de comunicación (Dader, 2001), se ha visto reflejado en un destacado interés de la investigación 
hacia el papel de las redes sociales durante las campañas electorales (Larsson; Kalsnes, 2014; Borondo et al., 2016; Casero-Ripollés, 2018; Heiss; Schmuck; Matthes, 2019).

No en vano, según el macrobarómetro preelectoral del CIS (2019) un 33\% de los encuestados dijeron informarse de la campaña electoral por las redes sociales, tan solo por detrás del 77\% que lo hace a través de la televisión. En 2019 Facebook era la red social con mas usuarios tanto en el mundo con 2.271 millones (Hootsuit, 2020) como en España con 22 millones (The Social Media Family, 2020), muy por encima de Twitter con 326 y 4,4 millones respectivamente. Sin embargo, la investigación sobre el uso de redes sociales en campaña electoral se ha centrado mayoritariamente en Twitter, por lo que Larsson (2015) concluye que es necesario aumentar la investigación académica sobre el uso de Facebook para comprender, de forma global, los usos políticos de las redes sociales (p. 18).

La creciente relevancia de las redes sociales en el espacio público y en la comunicación política se ha convertido en un lugar común en la bibliografía científica (p. ej., López-García, 2016; López-Meri; Marcos-García; Casero-Ripollés, 2020) siendo el ámbito en el que esta investigación se ha manifestado como dominante. La investigación al respecto, especialmente la procedente del área de Periodismo se ha centrado especialmente en Twitter (Segado-Boj, 2020). Más allá de la evidencia de que durante la campaña electoral los políticos incrementan su actividad en las redes, se ha destacado que el propio concepto de campaña electoral ha experimentado una

"redefinición ligada principalmente a la aparición de las redes sociales" (López-Meri, Marcos-García; Casero-Ripollés, 2020, p. 2).

Ello ha dado lugar al desarrollo de una línea de trabajos centrados en el papel de las redes sociales durante las campañas electorales (Muñiz, 2015), que toma como hito fundacional el uso que hizo el equipo de Barack Obama en las elecciones presidenciales de 2008 (Williams; Gulatti, 2008; Castells, 2009; Vaccari, 2010).

Aunque el aprovechamiento del potencial electoral de las redes sociales por parte de los partidos políticos españoles ha sido más tardío que en países anglosajones y europeos (Gamir-Ríos, 2016), lo cierto es que su uso en España ha sido constatado desde sus primeros pasos (Peytibi; Rodríguez; Gutiérrez-Rubí, 2008; Túñez; Sixto, 2011; Vallespín, 2011). Progresivamente han sido empleadas diferentes plataformas virtuales como las webs a partir de 2007, YouTube y blogs en 2008 (Gamir-Ríos, 2016), hasta ceder el protagonismo a Facebook y Twitter en la campaña de 2011 (Túñez; Sixto, 2011), siendo incorporadas posteriormente nuevas plataformas digitales como Telegram o WhatsApp a la cibercampaña electoral. Según Larsson y Kalsnes (2014), las redes sociales permiten eliminar la figura de los media gatekeepers, ofreciendo un "contacto directo con los seguidores potenciales" (p. 654).

Una vez que los partidos políticos han empezado a utilizar las redes sociales, las están empleando en gran parte para autopromocionar sus propios actos de campaña y las propuestas de su programa electoral (Sampietro; Valera, 2015; López-García, 2016; López-Meri; Marcos-García; Casero-Ripollés, 2017), así como para informar de su agenda mediática, tratar de movilizar para la acción y el voto (López-Meri; Marcos-García; Casero-Ripollés, 2020) y criticar al adversario (Suau-Gomila; Pont-Sorribas, 2019; Fenoll; Hassler, 2019). En este último aspecto, Heiss, Schmuck y Matthes (2019) encuentran que un tono negativo incrementa los comentarios y comparticiones.

\subsection{Partidos políticos como generadores de frames}

Igartua, Muñiz y Cheng (2005) definen frame como encuadre noticioso que

"remite al ángulo, enfoque, perspectiva o tratamiento de una información que se manifiesta en la elección, énfasis o importancia atribuida a diferentes elementos y, en particular, en la forma cómo covarían dichos elementos más o menos enfatizados en un texto" (p. 158).

Desde una perspectiva más amplia, el proceso de enmarcado, descrito gráficamente por autores como Scheufele (1999) o D’Angelo (2002), comprende diferentes etapas y actores, de entre los que la investigación parece haberse detenido especialmente en los medios de comunicación, dando lugar a lo que algunos denominan "perspectiva mediacéntrica" (López-Rabadán, 2010; Bartolomé-Castro; Rodríguez-Virgili, 2012), citando la necesaria mayor atención a la relación entre framing y poder que realizan autores como Vliegenthart y Van Zoonen (2011). Así, Rodríguez-Virgili, Sádaba-Garraza y La-Porte (2008) describen cómo este estudio prioritario del enmarcado ligado a la selección informativa ha ido siendo complementado por "un framing de las fuentes informativas" en la misma línea que ya Entman (1993) admitía que el framing no se reducía a los medios de comunicación (p. 21). En concreto, los políticos ocuparían "una posición destacada para ser los principales establecedores de los encuadres" (Bartolomé; Rodríguez-Virgili, 2012, p. 456). Sádaba-Garraza, Rodríguez-Virgili y Bartolomé-Castro (2012) detallan lo que denominan perspectiva estratégica del framing:

"No siempre son los medios de comunicación los primeros en definir los asuntos públicos. Liderar el modo en que se encuadran dichos asuntos es de vital importancia para establecer los términos en los que se desarrollará el debate público. En ese sentido, Lowell señaló ya en 1913 que es tarea de los partidos políticos, 'encuadrar los asuntos sobre los cuales la gente está llamada a dar una opinión'” (Lowell, 1921, p. 69).

Por tanto, como los frames definen la realidad pública, los políticos intentan poner en marcha mecanismos estratégicos para definir los asuntos a su conveniencia. 
A este estado se refiere Valera-Ordaz (2016) al afirmar que la investigación española y parte de la internacional tiende a asumir que la producción de los encuadres periodísticos

"se desarrolla sin ningún tipo de influencia extramediática (...) La batalla por la construcción de significados entre diversos actores sociales organizados en la arena mediática queda, por lo tanto, generalmente excluida de la agenda de investigación en España" (p. 20).

Contra esta situación, De-Vreese (2012) afirma que el impacto y el poder de los diferentes actores en el proceso de enmarcado están en un lugar central de la investigación, asegurando que

“los periodistas ejercen poca autonomía y participan sólo marginalmente en el proceso de enmarcado" (p. 368).

En su opinión, existe poca evidencia científica del reenmarcado periodístico y cuestionamiento de los marcos originales, de modo que son los marcos unilaterales introducidos por actores partidarios en el debate político (party frames, advocacy frames) los utilizados mayoritariamente en la cobertura mediática.
Los marcos partidistas son utilizados mayoritariamente en la cobertura mediática del debate político

La publicación de informaciones por actores diversos conduce a una competición entre marcos (Entman, 2003) o pugna de frames (Bartolomé; Rodríguez-Virgili, 2012), que ha sido literalmente etiquetada como "batalla de enmarcado" (battle of frames, framing battles) para muy diferentes objetos de estudio, como la campaña de confirmación para la Corte Suprema norteamericana (Gibson; Caldeira, 2009), la tramitación de leyes (Gruszczynski; Michaels, 2012), la legislación del tabaco (Ortiz, 2013), las políticas de lobby en la UE (Voltolini, 2013), los escándalos financieros (Just; Mouton, 2014) o el debate político, especialmente las campañas electorales (Slothuus; De-Vreese, 2010; Valera-Ordaz; López-García, 2014). También Park (2010) afirma que

"Ias campañas electorales se caracterizan por la batalla de marcos. Las afirmaciones de un partido son contradichas por otro (...) Para proveer unas bases más comprensibles para el pensamiento, los candidatos deben proceder con una competición de marcos" (p. 6).

\subsection{Engagement, nuevo objeto de deseo político y académico}

La creciente relevancia del concepto de engagement dentro de la investigación académica (Macnamara; Sakinofsky; Beattie, 2012; Pletikosa-Cvijikj; Michahelles, 2013; Triantafillidou et al., 2015; Sobaci; Hatipoğlu, 2017), se ha producido a pesar de ser un concepto que todavía se encuentra "en proceso de refinación" (Chan-Olmsted; Wolter; Wang, 2017, p. 9) y del escaso trabajo empírico sobre este proceso a través de las redes sociales (Gerodimos; Justinussen, 2015). Ballesteros-Herencia (2019a) define provisoriamente engagement como un

"proceso interactivo y bidireccional que implica compromiso o involucración entre unos sujetos (ciudadanos, trabajadores, clientes, usuarios de redes sociales) y unas organizaciones (administración pública, empresa, plataforma digital)" (p. 223).

Según Túñez y Sixto (2011) los partidos políticos españoles tratan de conseguir el máximo nivel de compromiso o engagement, ya que ésta sería la forma de tener éxito en Facebook (Niciporuc, 2014) o, incluso, se ha planteado su efecto conductual en los periodistas que tenderían a
La competición entre actores por definir la realidad ha conducido a una batalla por el enmarcado

"publicar noticias que se perciben con un buen desempeño en las redes sociales, lo que puede aumentar la participación de los usuarios a costa de producir una ciudadanía menos informada" (Valenzuela; Piña; Ramírez, 2017, p. 821).

Por último, se ha estudiado la posible relación entre el índice de engagement y los resultados electorales con conclusiones discordantes hasta la fecha (Hanson et al., 2010; Borondo et al. 2012; Deltell, 2012; Ballesteros-Herencia, 2019 b).

Torres-Nabel (2014) señala cómo las redes sociales y sus funciones generadoras de engagement (likes, retweets, hashtags, etc.) parecen dotar a la sociedad de

"una nueva forma de enmarcar los temas públicos importantes" (p. 321), si bien serían "unos cuantos actores influyentes" quienes seleccionan y enmarcan a través de dichas redes "los acontecimientos que deben considerarse importantes en la agenda pública" (p. 324).

Cohaila (2019) describe cómo el framing de la información publicada en redes sociales es similar a la de otros medios tradicionales.

\subsection{Objetivos y preguntas de investigación}

La articulación del estado de la investigación académica sobre framing y el uso de las redes sociales en campaña electoral nos plantea el objetivo general de esta investigación: detectar y describir los principales marcos utilizados por los partidos políticos españoles en sus páginas oficiales de Facebook durante las elecciones generales del 28 de abril de 2019. 
Para alcanzarlo se partió de la siguiente secuencia de preguntas de investigación:

1. ¿Cuáles fueron las estrategias de enmarcado de los partidos políticos en la información que difundieron a través de Facebook en esta campaña electoral?

2. ¿Compartieron los partidos políticos una estrategia de enmarcado similar o diferenciada en sus mensajes?

3. ¿Cuál fue el nivel de paralelismo o divergencia entre los frames más utilizados por los partidos y los que mayor interacción produjeron entre los usuarios de la red social?

\section{Método}

Para tratar de responder a las preguntas de investigación planteadas, se diseñó un análisis de contenido de los mensajes publicados en sus páginas oficiales de Facebook por los cinco principales partidos políticos españoles. Las variables de esos posts fueron tratadas mediante un análisis jerárquico de conglomerados para detectar inductivamente los frames con que las formaciones políticas enmarcan sus informaciones siguiendo el método propuesto por Matthes y Kohring (2008). Estos autores proponen una operacionalización concreta y transparente de los frames a partir de los cuatro componentes esenciales de la reconocida definición de Entman (1993, p. 52):

- definición del problema,

- atribución de las causas,

- evaluación moral, y

- tratamiento.

A continuación, realizan una detección y descripción inductiva de los marcos mediante el análisis estadístico de conglomerados (cluster analysis), de modo que identifican los frames a partir de los patrones en que se agrupan sistemáticamente las variables estudiadas. De esta forma se trata de superar la situación detectada por Matthes (2009) en gran parte de la bibliografía científica, donde citar una definición no siempre se traduce en

"que sea usada como una guía directa para la operacionalización" (p. 354).

Así, De Vreese (2012) asegura que la investigación del framing necesita mejorar el diseño de sus estudios, en concreto “cuando las definiciones generales son transformadas y operacionalizadas en los estudios empíricos" (p. 366).

En síntesis, la investigación del framing requeriría de una metodología

"acorde a la línea teórica en que se sustenta, de tal modo que una operativa transparente opere como motor de unos resultados derivados de un proceso coherente y fundamentado" (Ballesteros-Herencia, 2017, p. 308).

\subsection{Muestra}

La unidad de análisis natural fue el post, esto es, cada uno de los mensajes subidos por las formaciones políticas a Facebook. Se incluyó el período comprendido entre el 12 y el 28 de abril, o sea, toda la campaña electoral así como la jornada de reflexión y el día de las votaciones. Se capturaron todos los posts $(n=568)$ publicados en esta red social en el período citado por las cinco formaciones políticas que obtuvieron mayor número de votos en las elecciones generales (ver datos en tabla 1).

\subsection{Diseño y procedimiento}

Los mensajes de Facebook se capturaron mediante la extensión gratuita y de uso público Netvizz, creada por el investigador de la Universidad de Amsterdam Bernhard Rieder, cuyo uso científico aparece citado en más de 300 investigaciones (Hothanm, 2019). Esta aplicación permitió descargar el texto de los mensajes, la dirección de enlace, el tipo de contenido, la fecha y el número de me gusta, compartir y comentarios. Estas tres últimas variables sirvieron para cuantificar el nivel de engagement o compromiso por parte de los usuarios de Facebook con cada uno de los mensajes y de los marcos detectados.

Tabla 2. Mensajes en Facebook según partido político

\begin{tabular}{|l|c|c|}
\cline { 2 - 3 } \multicolumn{1}{c|}{} & \multicolumn{1}{c|}{$\begin{array}{c}\text { Número de } \\
\text { posts }\end{array}$} & Porcentaje \\
\hline PSOE & 167 & 29,4 \\
\hline Unidas Podemos & 154 & 27,1 \\
\hline Partido Popular & 99 & 17,4 \\
\hline Ciudadanos & 79 & 13,9 \\
\hline Vox & 69 & 12,1 \\
\hline Total & 568 & 100 \\
\hline
\end{tabular}

De este modo se obtuvo un total de 568 mensajes de los partidos políticos, que posteriormente fueron codificados por los autores de esta investigación. Las cuatro variables, y las categorías de cada una, que se consideraron para detectar los frames, se determinaron a partir de las utilizadas para la investigación de las redes sociales de los partidos políticos españoles en las campañas electorales de 2015 y 2016 por Muñiz y Ballesteros (2016), comprobando que eran ampliamente empleadas por la bibliografía científica al respecto (Williams; Gulati, 2013; López-García et al., 2015; Sampietro; Valera-Ordaz, 2015; López-Meri; Marcos-García; Casero-Ripollés, 2017; Suau-Gomila; Pont-Sorribes, 2019). Se alcanzó una definición operativa de síntesis de estas cuatro variables:

1. Actor: la atribución causal se asignó al sujeto protagonista de la acción. Las categorías posibles fueron a. Partido que postea; b. Seguidores; c. Adversarios y detractores; d. Partido contrario; e. Otros. 
2. Definición del problema o tema. Consistente en la acción que realiza el actor descrito, esto es, el contenido temático o campo semántico de los posts. Categorías: a. Eventos de campaña; b. Cuestiones políticas y propuestas programáticas; c. Actualidad de interés general no relacionados directamente con la campaña; $d$. Petición expresa de voto o referencias instrumentales al voto: e. Cuestiones económicas; f. Asuntos personales; g. Otros.

3. Evaluación. Se codificó en el sentido de que la acción descrita produjera beneficios o daños a determinados sectores: a. Atribuye beneficios para la sociedad o grupos sociales concretos, sin perjuicio para el resto; $b$. Atribuye perjuicios o riesgos para la sociedad o grupos sociales; c. Neutral o ambiguo.

4. Tratamiento. Recomendación que se propone para el tema tratado: a. Político, p.e. que el partido que postea gane las elecciones y consiga el Gobierno; b. Judicial: enjuiciamiento de los autores de los daños; c. Mediático-informativo; d. Económico; e. Otros.

Esta operacionalización metodológica es congruente con la línea metodológica propuesta por Igartua, Muñiz y Cheng (2005), descrita anteriormente, quienes proponen considerar los actores, acciones y atributos como

"indicadores manifiestos a partir de los cuales se puede reconstruir la estructura latente y las dimensiones subyacentes del tratamiento informativo" (p. 158).

Otras variables que también se tuvieron en cuenta en el libro de códigos y registradas mediante ficha de análisis fueron los datos de identificación básicos (número de unidad de análisis, autor del post y fecha) y número de interacciones en términos de Me gusta, Compartir y Comentar. Con estos últimos datos se trató de conocer el compromiso o engagement de los usuarios con cada página de Facebook.

Los datos obtenidos tras la captura automática con $\mathrm{Ne}$ tvizz y la codificación manual por parte de los codificadores fueron tratados estadísticamente con el programa SPSS. La fiabilidad intercodificadores fue puesta a prueba a partir de una muestra del $10 \%$ de los mensajes $(n=58)$, resultando un coeficiente de acuerdo medio del 90,52\%. Igartua (2006) considera el coeficiente de acuerdo como medición

"especialmente apropiada cuando se utilizan variables de tipo categorial, aquellas que adoptan un nivel de medida nominal",

como era el caso de este estudio. También se calculó un valor medio de la Kappa de Cohen para las cuatro variables principales del 0,786. Esta medida es indicada

"cuando se usa medidas nominales y todos los desacuerdos se consideran equivalentes" (Riffe et al., 2019, p. 123).

Los niveles considerados adecuados son el 80\% para el coeficiente de acuerdo y el 0,7 para la Kappa de Cohen (Igartua, 2006).

Con estas variables se llevó a cabo un análisis jerárquico de conglomerados con el método de Ward utilizando el programa SPSS, a partir del cual se seleccionaron cuatro frames o marcos utilizados por los partidos políticos en sus páginas de Facebook durante la campaña electoral de abril de 2019. La utilización de técnicas de análisis de conglomerados para detectar frames ha sido considerado un método fiable, riguroso y preciso (Miller; Riechert, 2001, p. 119), habiendo sido aplicado al contexto específico de las campañas electorales (Fenoll; Rodríguez-Ballesteros, 2017).

\section{Resultados}

A continuación se exponen los principales resultados de esta investigación. En primer lugar, se detallan los actores y contenidos más frecuentes en los mensajes de los partidos políticos durante la campaña electoral. En segundo lugar se describen los cuatro frames detectados mediante análisis de conglomerados. Por último se realiza un análisis de las interacciones de las cuentas de usuarios con cada marco descrito.

\subsection{Actores y contenidos}

El actor principal de los mensajes de los partidos políticos en Facebook fue el propio partido que posteaba con más de cuatro de cada cinco posts, seguido a distancia por una cierta atención al partido contrario, en uno de cada 10 mensajes. De una manera más marginal, actores adversarios, detractores o vistos como enemigos por el partido propio aparecieron en uno de cada 25 mensajes analizados, mientras que los simpatizantes lo hicieron en sólo uno de cada 50.

Dos temas, eventos de campaña y cuestiones políticas y programáticas, acumularan el 82,3\% de los mensajes. Todos los partidos trataron de mostrar su mejor imagen en mítines y actos. En el caso de Vox fueron frecuentes los éxitos de convocatoria como el "Ileno en San Sebastián y Bilbao pese al acoso de la mafia proetarra" (Unidad de Análisis 811), o que "la \#EspañaViva desbordó todas las previsiones en Valladolid" (UA 814) o "arrasa en Albacete. El Palacio de Congresos se queda pequeño y un millar de personas se quedan en el exterior" (UA 831).

Ciudadanos mostró actos Ilamativos como la quedada motera con su líder Albert Rivera "subido en una moto por el recorrido" (UA 51), cercanos como las cañas de cerveza de simpatizantes con Inés Arrimadas en León o Huelva (UA 62, 81) o conflictivos como su presencia en Alsasua y Rentería "para defender la democracia y la libertad" (UA 44, 47, 49) frente 
a los "insultos, gritos y caceroladas de los intolerantes" (UA 60).

También Unidas Podemos informó de enfrentamientos en sus actos como el de Nalda donde "unos provocadores han acudido a gritar iViva España!" (UA336).

El PP se refirió a actos sectoriales como el encuentro de Pablo Casado con empresarios en Asturias (UA 461), pero también del "lleno absoluto en el auditorio de Alicante" (UA 494), o de la "impresionante llegada a nuestra sede del próximo presidente del Gobierno" tras el debate televisivo (UA 512).

Por su parte, si bien en el PSOE fue habitual un formato austeramente informativo del tipo "Pedro Sánchez participa en un mitin en" o "Acto de Pedro Sánchez en" determinada localidad, tampoco desaprovechó la oportunidad cuando pudo anotarse un tanto en popularidad en posts como "Más de 3000 personas se han acercado esta tarde a ver el acto de Pedro Sánchez en Gijón” (UA 673) o “Más de 4.000 personas en Barcelona” (UA 689).

Las cuestiones políticas y programáticas de las formaciones políticas se desarrollaron en torno a una serie de lugares comunes. Los más frecuentes hacían referencia a la Sanidad, la Educación o la Economía, mientras que los menos numerosos fueron el independentismo, la eutanasia o el mundo rural. En esa tónica, mientras $P P$ o Vox prometieron bajar impuestos, PSOE y Unidas Podemos incidieron en la mejora de las pensiones, las condiciones dignas de trabajo y el mantenimiento del Estado del Bienestar. También las cuestiones relacionadas con el feminismo fueron un tema común a todos los partidos: el PSOE hizo especial hincapié en él en una decena de mensajes, pero el resto de formaciones apenas le dedicaron uno o dos posts, en ocasiones motivados por la necesidad de defenderse. Así, a raíz del debate televisivo entre candidatos el PSOE posteó el 22 de abril: "Pedro Sánchez Pérez-Castejón: Señor Casado me gustaría que le dijera a sus candidatos y también a sus candidatas que un NO es un NO" (UA 639). Unas horas más tarde el Partido Popular manifestó que estaba en contra de la violencia de género y que "la acusación de Sánchez es deleznable. Utilizar el dolor de las mujeres para atacar al líder de la oposición es vergonzoso" (UA 524). En su único mensaje dedicado a esta cuestión Vox identificaba culpables: "Ni un euro público más para los lobbies del feminismo supremacista que propagan odio y división" (UA 832).

Pero cada partido también sacó a la palestra alguna cuestión política diferenciada, de modo puntual como los ataques directos a Pedro Sánchez con motivo de su tesis o su uso del Falcon por parte del $P P$, la defensa de los animales y la seguridad vial de Ciudadanos o alguna loa aislada de Unidas Podemos a la República, o de forma más sistemática como Vox y PSOE. Así, entre las cuestiones políticas y programáticas de Vox destacó su personal defensa de la españolidad con el uso del hashtag \#EspañaViva en el $26 \%$ de sus mensajes, sus ataques a la "derechita cobarde" o a la "dictadura progre". Por su parte el PSOE tuvo dos claros ejes de campaña, por un lado, la citada defensa del feminismo, y por otro sus frecuentes alusiones con distinto formato a las "tres derechas" y "el trío de Colón".

El siguiente tema más empleado, la petición de voto, se quedó en el $12,3 \%$, mientras que las cuestiones económicas aparecieron en un $2,6 \%$. El tratamiento político dominante $(82,9 \%)$ de la información de los partidos, tan solo dejó un cierto hueco al tratamiento mediático o informativo de estos temas $(9,2 \%)$. Finalmente, y de un modo coherente, los posts realizaron una evaluación prioritariamente positiva $(70,2 \%)$ de las acciones protagonizadas (en su mayor parte) por los partidos que publicaban dicho contenido (ver los datos en la tabla 3).

\subsection{Marcos informativos de los partidos po- líticos}

Para detectar los posibles marcos en que se agrupaban los mensajes de los partidos se realizó un análisis jerárquico de conglomerados mediante el método de Ward y la distancia euclidiana al cuadrado, método considerado como adecuado por autores como Breckenridge (2000) o Hands y Everitt (1987), según recogen Matthes y Kohring (2008). Dado que la elección del número de conglomerados no se realiza de modo automático, sino que participa el criterio del investigador, la determinación y validación del número óptimo de conglomerados se realizó en tres fases cualitativamente diferentes.
Tabla 3. Presencia de elementos de enmarcado $(n=568)$

\begin{tabular}{|c|c|c|}
\hline & & $\begin{array}{c}\text { Presencia en } \\
\text { posts (\%) }\end{array}$ \\
\hline \multirow{5}{*}{ Actor } & Partido que postea & 82,2 \\
\hline & Partido contrario & 10,6 \\
\hline & Adversarios & 4,2 \\
\hline & Simpatizantes & 2,8 \\
\hline & Otros & 0,2 \\
\hline \multirow{7}{*}{ Tema } & Eventos de campaña & 44,4 \\
\hline & Cuestiones políticas y programáticas & 37,9 \\
\hline & Petición de voto & 12,3 \\
\hline & Cuestiones económicas & 2,6 \\
\hline & Actualidad & 1,1 \\
\hline & Otros & 0,9 \\
\hline & Asuntos personales & 0,9 \\
\hline \multirow{5}{*}{ Tratamiento } & Político & 82,9 \\
\hline & Mediático, informativo & 9,2 \\
\hline & Económico & 1,9 \\
\hline & Judicial & 0,9 \\
\hline & Otros & 0,4 \\
\hline \multirow{3}{*}{ Evaluación } & Beneficios para la sociedad & 70,2 \\
\hline & Perjuicio para la sociedad & 14,6 \\
\hline & Neutral o ambiguo & 15,1 \\
\hline
\end{tabular}


En una primera fase estadística se analizaron los coeficientes del diagrama de aglomeración, detectándose un acentuado salto en las diferencias entre ellos para los cinco últimos casos, lo que aconseja optar por cuatro clústers, opción también corroborada por la observación del dendograma. En una segunda fase se contrastó la coherencia lógica e informativa de decantarse alternativamente por la formación de tres, cuatro o cinco conglomerados. Considerar tres conglomerados hacía perder el marco de tratamiento mediático, mientras que ampliar la solución a cinco grupos, no sólo hacía aparecer un pequeño clúster $(n=20)$ con 14 posts sobre economía y 6 de otros temas, sino que agrupaba la petición de voto con cuestiones políticas, separando un grupo propio para eventos, lo que arrojaba una solución menos clara e interpretable.

Por tanto, se optó por considerar cuatro conglomerados, validándose finalmente esta solución, en una tercera fase, mediante los dos métodos estadísticos seleccionados por Rodelo y Muñiz (2016). En primer lugar, se volvió a realizar un análisis jerárquico de conglomerados utilizando una medida diferente, en este caso la distancia euclidiana, mostrándose correlación $(p<0,001)$ entre las dos agrupaciones de conglomerados formadas por ambos métodos. En segundo lugar, se dividió aleatoriamente la muestra en dos partes. Tras aplicarse a ambas muestras el análisis de conglomerados, la correlación entre las medias de los items considerados también mostró significación estadística $(p<0,001)$.

De este modo se consideraron cuatro marcos informativos de los partidos políticos como resultado de las cuatro categorías de la nueva variable nominal que produjo el análisis jerárquico de conglomerados, siguiendo el método aplicado por Matthes y Kohring (2008) o Rodelo y Muñiz (2016).

El marco más habitual fue el que agrupaba eventos de campaña y cuestiones políticas con el $61,3 \%$ ( $n=348)$ del total de los mensajes. En este frame el actor protagonista casi único fue el partido que posteaba, con un $98,3 \%$ ( $n=342$ ), junto a otros 6 mensajes protagonizados por simpatizantes y seguidores. De un modo lógico, el partido propio realizó acciones positivas en el $80 \%$ de las ocasiones, quedando el $20 \%$ restante para evaluaciones neutras o ambiguas. Se catalogó un tratamiento político de estas acciones en todos los casos.

El segundo frame más frecuente $(16,4 \%)$ se denominó “Marco de petición de voto", en tanto el partido que posteaba como actor preponderante pedía el voto en el 75\% de los mensajes. La agrupación estadística también detectó cercanía hacia estos mensajes de aquellos que trataban de acciones económicas (15,51\%).

En tercer lugar se etiquetó como "Marco del partido rival" a aquellos posts donde el sujeto protagonista era el partido contrario $(69,2 \%)$ o bien adversarios del partido autor del mensaje $(25,6 \%)$, cuyas posturas políticas y eventos eran considerados como perjudiciales para la sociedad $(95,9 \%)$.

En último lugar, el $8 \%$ de total de los posts analizados se trataron con el "Marco del tratamiento mediático", en tanto el partido que posteaba informaba de eventos de campaña, mediante vídeos y enlaces de sus intervenciones en mítines, debates, entrevistas con medios de comunicación o publicación de artículo en prensa (ver los datos en la tabla 4).

Tabla 4. Marcos identificados mediante análisis jerárquico de conglomerados

\begin{tabular}{|c|c|c|c|c|c|}
\hline Variable & Categorías & $\begin{array}{l}\text { Marco de eventos y } \\
\text { cuestiones políticas }\end{array}$ & $\begin{array}{c}\text { Marco de petición } \\
\text { de voto }\end{array}$ & $\begin{array}{c}\text { Marco del partido } \\
\text { rival }\end{array}$ & $\begin{array}{l}\text { Marco del tratamien- } \\
\text { to mediático }\end{array}$ \\
\hline & $\mathrm{n}=568$ & 348 & 93 & 78 & 49 \\
\hline \multirow{5}{*}{ Actor } & Partido que postea & 98,3 & 88,2 & 0 & 91,8 \\
\hline & Simpatizantes & 1,7 & 3,2 & 3,8 & 8,2 \\
\hline & Adversarios & 0 & 5,4 & 25,6 & 0 \\
\hline & Partido contrario & 0 & 3,2 & 69,2 & 0 \\
\hline & Otros & 0 & 0 & 1,3 & 0 \\
\hline \multirow{7}{*}{ Tema principal } & Cuestiones políticas & 42,8 & 0 & 79,5 & 6,1 \\
\hline & Eventos & 56,3 & 0 & 16,7 & 87,8 \\
\hline & Asuntos personales & 0,9 & 0 & 0 & 4,1 \\
\hline & Actualidad & 0 & 3,2 & 2,6 & 2 \\
\hline & Petición de voto & 0 & 75,3 & 1,3 & 0 \\
\hline & Cuestiones económicas & 0 & 15,1 & 0 & 0 \\
\hline & Otros & 0 & 6,5 & 0 & 0 \\
\hline \multirow{3}{*}{ Evaluación } & Beneficios & 80,9 & 87,1 & 5,1 & 71,4 \\
\hline & Perjuicios & 0,0 & 8,6 & 94,9 & 0 \\
\hline & Neutral o ambiguo & 18,1 & 2,2 & 0 & 24,5 \\
\hline \multirow{5}{*}{ Tratamiento } & Político & 100 & 77,4 & 82,1 & 0 \\
\hline & Económico & 0 & 9,7 & 0 & 4,1 \\
\hline & Mediático, informativo & 0 & 6,5 & 2,6 & 89,8 \\
\hline & Otros & 0 & 0 & 1,3 & 4,1 \\
\hline & Judicial & 0 & 1,1 & 3,8 & 2 \\
\hline
\end{tabular}


A continuación se pudo comprobar la existencia de una asociación estadísticamente significativa $(p<0.001)$ entre las cuatro variables que se utilizaron para definir los marcos y cada una de las formaciones políticas $\left(\right.$ Actor $\chi^{2}(16)=55,568$; Tema $\chi^{2}(24)=87,171$; Evaluación $\chi^{2}(12)=43,005$; Tratamiento $\left.\chi^{2}(20)=62,764\right)$. Para profundizar en el análisis se calcularon los residuos tipificados corregidos de cada casilla. De este modo cada partido político quedó caracterizado por un uso característico de los dispositivos de enmarcado.

Los datos reflejan cómo el PSOE destacó por realizar una campaña en positivo a través de Facebook, con sólo el 5\% de mensajes de evaluación negativa y escasas referencias al partido contrario (6\%). El grueso de sus mensajes se dedicó a informar de sus propios planteamientos políticos y eventos, siendo el partido que más pidió el voto, en casi uno de cada cuatro mensajes (24\%). En el extremo opuesto, Partido Popular y Unidas Podemos dedicaron en torno al $20 \%$ de sus posts a informar sobre acciones negativas de partidos rivales y adversarios. En concreto Unidas Podemos fue la formación que más utilizó como actor de sus mensajes a todo tipo de contrincantes: las cloacas del Estado (UA 339, 417), empresas, bancos o "el sistema" (UA 340), los fondos buitre (UA 351), los medios de comunicación (UA 361), las multinacionales (UA 147), la censura de WhatsApp (UA 400, 404), "los corruptos y los que no pagan impuestos" (UA 420), y llegando a identificar a personas concretas ("Ana Botín, Florentino Pérez o Villar Mir tienen mucho más poder que vosotros e incluso que los representantes públicos. Así es todos los días del año menos el domingo", UA 449).

Vox fue el segundo partido que más se refirió a este tipo de actores antagonistas: concretos como los medios de comunicación ("La Sexta, esa cadena que señalaba a nuestros votantes en Marinelada como si fueran judíos en la Alemania nazi... tendrá que justificar el uso de su concesión pública", UA 530; o bien "los periódicos de la derechita cobarde", UA 835), o más generales, como "la dictadura progre" (UA 856).

Unidas Podemos fue el partido que mayor variedad temática empleó en sus mensajes, dedicando casi un 15\% de sus mensajes a temas de actualidad, económicos y otros, mientras que el resto de partidos sólo reservaron a estas tres categorías entre el 0 y $3 \%$ de sus mensajes. En consonancia con estos datos, Unidas Podemos trató los temas de un modo mediático o económico en un 23,3\% de ocasiones, mientras otros partidos oscilaron entre el $2 \%$ del PP y el $11 \%$ del PSOE.

Finalmente, Vox enmarcó a sus simpatizantes como actores en un porcentaje de ocasiones del 8,7\%, significativamente superior al de sus rivales, frente al casi nulo protagonismo en las páginas del PSOE (0,0\%) o del PP (1\%). Así ciertos mensajes de la formación de Santiago Abascal fueron protagonizados por "todos los simpatizantes que estáis colaborando con vuestros vídeos" (UA 837), incluían un vídeo donde se mostraba "lo que pasa cuando un progre quiere tocarle las narices a un currante" (UA 846), explicaban "por qué los jóvenes votan a Vox" (UA 857), o agradecían su esfuerzo a los voluntarios (UA 861). También utilizó Vox los asuntos personales en mayor porcentaje de casos que sus rivales, por ejemplo, para mostrar en un vídeo la "historia" de Santiago Abascal, "43 años sin rendirse. No hay mejor aval el valor de un político" (UA 509).

Tabla 5. Presencia de elementos de enmarcado según el partido político

\begin{tabular}{|c|c|c|c|c|c|c|c|}
\hline Variable & Categoría & Total & PSOE & PP & $\begin{array}{l}\text { Unidas } \\
\text { Podemos }\end{array}$ & C's & Vox \\
\hline \multirow{5}{*}{ Actor } & Partido que postea & 82,6 & $93,4^{+}$ & 78,8 & 76,0 & 82,3 & 76,8 \\
\hline & Simpatizantes & 2,8 & $0,0^{-}$ & 1,0 & 4,5 & 2,5 & $8,7^{+}$ \\
\hline & Adversarios & 4,4 & 0,0 & 2,0 & $10,4^{+}$ & 2,5 & 7,2 \\
\hline & Partido contrario & 10,0 & $6,0^{-}$ & $18,2^{+}$ & 9,1 & 12,7 & 7,2 \\
\hline & Otros & 0,2 & 0,6 & 0,0 & 0,0 & 0,0 & 0,0 \\
\hline \multirow{7}{*}{ Tema } & Eventos de campaña & 44,4 & $35,3^{-}$ & 45,5 & 41,6 & $57,0^{+}$ & $56,5^{+}$ \\
\hline & Asuntos personales & 0,9 & 0,6 & 1,0 & 0,6 & 0,0 & 2,9 \\
\hline & Cuestiones políticas & 37,7 & 38,9 & 38,4 & 36,4 & 38,0 & 36,2 \\
\hline & Actualidad & 1,1 & 0,6 & 1,0 & $2,6^{+}$ & 0,0 & 0,0 \\
\hline & Petición de voto & 12,5 & $24,0^{+}$ & 13,1 & $7,1^{-}$ & $5,1^{-}$ & $4,3^{-}$ \\
\hline & Economía & 2,5 & 0,6 & 1,0 & $7,8^{+}$ & 0,0 & 0,0 \\
\hline & Otros & 1,1 & 0,0 & 0,0 & $3,9^{+}$ & 0,0 & 0,0 \\
\hline \multirow{3}{*}{ Evaluación } & Beneficios & 70,2 & $77,8^{+}$ & 63,6 & 58,4 & 77,2 & 79,7 \\
\hline & Perjuicio & 14,6 & $5,4^{-}$ & $21,2^{+}$ & $19,5^{+}$ & 16,5 & 14,5 \\
\hline & Neutral o ambiguo & 13,6 & 15,6 & 15,2 & 17,5 & 6,3 & $5,8^{-}$ \\
\hline \multirow{5}{*}{ Tratamiento } & Político & 87,5 & 91,6 & $94,9^{+}$ & 75,9 & 89,9 & 88,4 \\
\hline & Judicial & 0,9 & 0,0 & 0,0 & 0,6 & $3,8^{+}$ & 1,4 \\
\hline & Mediático & 9,2 & 6,6 & $2,0^{-}$ & $17,5^{+}$ & 6,3 & 10,1 \\
\hline & Económico & 1,9 & 1,2 & 0,0 & $5,8^{+}$ & 0,0 & 0,0 \\
\hline & Otros & 0,5 & 0,6 & $2,0^{+}$ & 0,0 & 0,0 & 0,0 \\
\hline
\end{tabular}

Nota: $\mathrm{n}=568$. Datos en porcentaje.

-/+ Casillas con residuos tipificados corregidos significativos. 
Por su parte, Ciudadanos fue la única formación política que realizó un tratamiento judicial de la información en un cierto número de casos (3,8\%), por ejemplo, para pedir a la Fiscalía que interviniera por las protestas en un acto de este partido en Rentería (UA 63), mientras las demás formaciones oscilaron entre el 0 y $1 \%$ (ver los datos en la tabla 5).

El análisis de cómo combinaron los partidos políticos estos elementos para enmarcar sus mensajes en Facebook permitió detectar diferencias estadísticamente significativas en cómo las formaciones políticas emplearon estos marcos $\left(\chi^{2}(12)=24,982, p<0,001\right)$. De este modo, los residuos tipificados corregidos mostraron que el PSOE empleó el marco de petición de voto de una forma significativamente mayor que el resto de formaciones, mientras que utilizó menos el marco del partido rival que el resto de contendientes. Unidas Podemos se concentró más que otros partidos en el marco del tratamiento mediático, mientras que Ciudadanos lo hizo en informar de sus propios eventos y propuestas (ver los datos en la tabla 6).

Tabla 6. Marcos utilizados por los partidos políticos

\begin{tabular}{|l|c|c|c|c|c|}
\cline { 2 - 6 } \multicolumn{1}{c|}{} & PSOE & PP & Unidas Podemos & C's & Vox \\
\hline Marco de eventos y cuestiones políticas & 62,3 & 63,6 & $49,4^{-}$ & $73,4^{+}$ & 68,1 \\
\hline Marco de petición de voto & $24,6^{+}$ & 13,1 & 20,8 & $5,1^{-}$ & $1,3^{-}$ \\
\hline Marco del partido rival & $6,6^{-}$ & 19,2 & 16,2 & 15,2 & 15,9 \\
\hline Marco del tratamiento mediático & 6,6 & $4,0^{-}$ & $13,6^{+}$ & 6,3 & 13,7 \\
\hline & 100 & 100 & 100 & 100 & 100 \\
\hline
\end{tabular}

Nota: $\mathrm{n}=568$. Datos en porcentaje.

-/+ Casillas con residuos tipificados corregidos significativos.

\subsection{Engagement de los marcos de los partidos políticos}

Por último, el análisis trató de cuantificar las interacciones de los usuarios que recibieron cada uno de estos marcos, comprobándose que los marcos detectados recibían un diferente nivel de compromiso de los usuarios de Facebook. La prueba Anova mostró significatividad para las tres variables de engagement consideradas: $\operatorname{Likes}(F(3)=9,100, p<0,001)$, Shares $(F(3)=5,265, p<0,01)$ y Comments $(F(3)=5,311, p<0,01)$.

El marco que mayor compromiso produjo entre sus seguidores fue el de tratamiento mediático, con más del doble de likes que el siguiente con mayor número, el marco del partido rival. Éste, a su vez, obtuvo casi el doble de comparticiones que los dos últimos. El marco de eventos y cuestiones políticas, tercero en total de interacciones, tan solo resaltó relativamente en número de comentarios, siendo el segundo de los cuatro marcos. La petición de voto obtuvo el menor número de interacciones en las tres variables consideradas (ver los datos en la tabla 7).

Se detectó una correlación negativa entre el uso de frames por parte de los partidos y las interacciones que recibieron $(r=-0,396, p<0,05)$. De este modo los dos marcos menos utilizados por los partidos políticos fueron los que obtuvieron mayores índices de engagement.

Tabla 7. Engagement con los marcos políticos

\begin{tabular}{|l|c|c|c|c|c|}
\cline { 2 - 6 } \multicolumn{1}{c|}{} & $\mathbf{n}$ & $\begin{array}{c}\text { Número medio } \\
\text { de likes (DT) }\end{array}$ & $\begin{array}{c}\text { Número medio } \\
\text { de shares (DT) }\end{array}$ & $\begin{array}{c}\text { Número medio } \\
\text { de comments (DT) }\end{array}$ & $\begin{array}{c}\text { Engagement } \\
\text { total (DT) }\end{array}$ \\
\hline Marco del tratamiento mediático & 49 & $3.541(5.431)$ & $1.837(3.335)$ & $954(1709)$ & $6.332(9.111)$ \\
\hline Marco del partido rival & 78 & $1.646(2.751)$ & $1.433(2.952)$ & $402(786)$ & $3.481(6.336)$ \\
\hline Marco de eventos y cuestiones políticas & 348 & $1.604(2.427)$ & $788(1.765)$ & $603(1.146)$ & $2.995(4.652)$ \\
\hline Marco de petición de voto & 93 & $1.111(.1168)$ & $762(1.388)$ & $262(282)$ & $2.135(2.435)$ \\
\hline Total & 568 & $1.696(2.776)$ & $963(2.113)$ & $549(1.086)$ & $3.209(5.268)$ \\
\hline
\end{tabular}

Nota: $\mathrm{n}=568$. DT = desviación típica.

Finalmente se analizó el engagement que recibieron estos frames por parte de los seguidores de cada uno de los partidos. Tan sólo se detectó una fuerte correlación $(r=0,986, p<0,05)$ en el caso del PSOE, mientras que la correlación fue débil en el caso del $P P(r=0,22)$, negativa para Unidas Podemos y Ciudadanos y no significativa $(p<0,05)$ para Vox. La querencia descrita del Partido Popular por emplear el marco del partido rival no fue refrendada por sus usuarios, que relegaron este frame al último lugar en interacciones. En cambio, la mayor utilización del marco del tratamiento mediático por parte de Unidas Podemos, obtuvo un alto nivel de engagement. Por el contrario, Ciudadanos relegó el empleo de este frame del tratamiento mediático, a pesar de que fue con el que más interacciones registró. Por su parte, mientras que el marco más frecuente en los mensajes de Vox, el de eventos y cuestiones políticas, fue el segundo con menor número de interacciones, el marco menos utilizado por este partido fue el segundo en términos de compromiso. Los seguidores de Vox mostraron su mayor engagement con el marco del partido rival (ver los datos en la tabla 8). 
Tabla 8. Engagement con los marcos de cada partido

\begin{tabular}{|l|c|c|c|c|c|}
\cline { 2 - 6 } & PSOE & PP & $\begin{array}{c}\text { Unidas Pode- } \\
\text { mos }\end{array}$ & C's & Vox \\
\hline Marco del tratamiento mediático & 920 & 999 & 11.427 & 3.945 & 4.555 \\
\hline Marco del partido rival & 1.013 & 951 & 5.440 & 964 & 8.611 \\
\hline Marco de eventos y cuestiones políticas & 1.893 & 1.065 & 4.846 & 1.362 & 7.159 \\
\hline Marco de petición de voto & 1.143 & 1.125 & 3.430 & 933 & 7.860 \\
\hline
\end{tabular}

Nota: Número promedio de interacciones por mensaje, $n=568$.

\section{Discusión y conclusiones}

Las elecciones del 28 de abril de 2019 fueron un nuevo escenario para la exploración de la campaña electoral en redes sociales. Las investigaciones anteriores habían subrayado que su principal uso por parte de los actores políticos era la difusión de información, sobre todo de producción propia, aprovechando las ventajas de autoproducción que las plataformas digitales ofrecen (López-Meri; Marcos-García; Casero-Ripollés, 2017).

Respondiendo a la primera pregunta de investigación, se detectó que el frame más utilizado por los partidos políticos en Facebook fue el marco de eventos y cuestiones políticas que se utilizó de un modo mayoritario, en casi dos de cada tres mensajes (61,23\%), en consonancia con estudios precedentes (Sampietro; Valera-Ordaz, 2015; López-García, 2016). Como describían López-García et al. (2015) para Twitter, este frame conseguiría combinar dos dimensiones de la actividad política: los actos de campaña y la difusión de mensajes clave. Sólo Unidas Podemos realizó un uso significativamente menor de este marco, empleándolo en menos de la mitad de sus mensajes, lo que concuerda con López-Meri, Marcos-García y Casero-Ripollés (2017) quienes encontraron que en las elecciones de 2016 todos los actores, a excepción de Pablo Iglesias, utilizaron Twitter principalmente para informar de sus propuestas.

El resto de frames no alcanzaron en ningún caso el $20 \%$. Así, el segundo marco más empleado, el de petición de voto supuso el $16,37 \%$ de los posts publicados durante la campaña electoral, mientras que el del partido rival ocupó el 13,73\% del espacio y el marco de tratamiento mediático, el 8,62\%.

Salvo en el caso del frame de partido rival, el actor de los posts fue el partido que posteaba, cuyas acciones reportaban beneficios para la sociedad en porcentajes superiores al $70 \%$ de los casos, y efectos neutrales en el resto. Por el contrario, en el marco del partido rival los actores fueron el partido contrario $(69,2 \%)$ y diferentes tipos de adversario $(25,6 \%)$.

Estas dinámicas de enmarcado definen una estrategia de largo recorrido en las últimas citas electorales por parte de los partidos políticos. En ese sentido, se advierte que los frames respondían a una identidad comunicativa adscrita a elecciones anteriores más que a unos principios ideológicos o programáticos (que podrían haber incidido más en cuestiones sociales o de empleo). Por tanto, se podría concluir que los partidos plantearon su comunicación política desde presupuestos institucionales que afectó a todas las dimensiones de la campaña, incluidas las redes sociales.

Respecto a la segunda pregunta de investigación, se registraron notables diferencias en el uso de los elementos de enmarcado entre las formaciones políticas. De este modo se encontró cómo el partido gobernante, el PSOE, optó por realizar una campaña en positivo, institucional y centrada en pedir el voto de forma directa, siendo el partido que más raramente empleó el marco del partido rival, tres veces menos que el Partido Popular, y menos de la mitad que cualquier otra formación. Por el contrario, fue el partido que más empleó el marco de petición de voto, incluyéndolo en casi una cuarta parte de sus mensajes.

En el otro extremo, el PP, asumió su papel de oposición siendo el que más veces criticó al partido contrario, cumpliendo lo que Suau-Gomila y Pont-Sorribes (2019) denominan "sentido de contracampaña", que López-Meri, Marcos-García y Casero-Ripollés (2017) y Fenoll y Hassler (2019) adscriben a partidos de oposición criticando al partido en el Gobierno.

Por su parte, la campaña en Facebook de Unidas Podemos se caracterizó por referirse más que ningún otro partido a la presencia de su formación y sus líderes en diferentes medios de comunicación, así como por ser el segundo partido que más empleó el marco del partido rival, concretamente por incluir más que ningún otro partido a los adversarios y detractores como actores en sus mensajes. Así, Unidas Podemos actuó en el sentido descrito por López-Meri, Marcos-García y Casero-Ripollés (2020) para las elecciones de 2016 cuando afirman que algunos líderes

"priorizan sus intervenciones en medios de comunicación y las publicitan a través de Facebook, por encima de contenidos relacionados con los actos de campaña o el programa electoral".

Además, Unidas Podemos trató de polemizar no ya con otros partidos, sino también con diferentes "enemigos poderosos": los ataques a la cloaca mediática, a Florentino Pérez, Ana Botín, etc.

Ciudadanos por su parte se centró en informar de sus actividades de campaña y de sus propuestas políticas, que en conjunto sumaron casi tres de cada cuatro de sus mensajes. Finalmente, Vox fue el partido que mayor
Todos los partidos priorizan la información sobre sus actos y propuestas electorales 
protagonismo dio en sus mensajes a sus simpatizantes, casi el doble que el segundo que más lo hizo, Unidas Podemos, así como por ser el segundo partido que más se refirió a diferentes tipos de adversarios. Vox utilizó así un marco conflictivo en el que España y sus seguidores se veían amenazados por una serie de enemigos. Y a la vez compensaba esta situación animando a sus seguidores y creando sentimiento de pertenencia a grupo, por ejemplo, generando identificación al ser el partido que más utilizó los asuntos personales como tema informativo. Y también mostrando éxitos de convocatoria, ya que informó mucho más que el resto, salvo Ciudadanos, de sus populosos eventos de campaña.

En definitiva, la estrategia temática de campaña de cada partido se evidenció en sus elementos de enmarcado en Facebook. Los dos partidos que aspiraban a liderar el futuro gobierno optaron por una campaña institucional, pero con relevantes matices. El PSOE habló casi exclusivamente del partido y se centró en pedir el voto de forma directa. Posiblemente condicionado por su débil situación parlamentaria (matemáticamente) y que-según se interpretaba-convocaba elecciones para mejorar dicha posición y ganar oxígeno, como anunciaban las encuestas. El Partido Popular se mantuvo en esa campaña institucional, pero con un matiz negativo: asumió su papel de oposición y se centró en atacar al PSOE y su posible gobierno. En definitiva, aceptó el relato propuesto por el PSOE: que estas elecciones se dirimían en "Sánchez sí" o "Sánchez no".

En último lugar, la tercera pregunta de investigación obtuvo una respuesta clara. Existe una correlación negativa entre los marcos que más interacciones reciben por parte de las cuentas de Facebook y los que son más utilizados por los partidos políticos, por lo que se corrobora el bajo grado de similitud entre las agendas de los políticos y la agenda pública (Suau-Gomila, 2020). Así se pudo comprobar que el marco que más veces emplearon las formaciones políticas, el de eventos y cuestiones políticas, fue el segundo con menos interacciones, mientras que el marco con mayor engagement, el mediático, fue el que menos apareció. El marco de petición de voto, segundo más habitual, fue el que menos compromiso obtuvo de los usuarios, y el marco del partido rival, penúltimo en orden de apariciones, fue el segundo que más interacción provocó en los usuarios. Esta preferencia de los usuarios por mensajes en los que se critica a los partidos contrarios concuerda con lo encontrado por Suau-Gomila (2020) en las elecciones de 2015 y 2016. También Heiss, Schmuck y Matthes (2019) describen que la información negativa incrementa el número de likes, comentarios y comparticiones.

Desagregando estos resultados, y comparando el engagement que recibió cada uno de estos marcos únicamente por sus propios seguidores, se detectó paralelismo entre marcos más empleados y mayor número de interacciones sólo en el caso del PSOE. También Unidas Podemos obtuvo el mayor compromiso en su apuesta por el marco de tratamiento mediático. El resto de las formaciones políticas no lograron traducir en número de interacciones su inclinación particular por un tipo de enmarcado.

Sintetizando las respuestas a estas preguntas de investigación, se concluye que los partidos políticos confrontaron estrategias de enmarcado diferenciadas en función de su particular posición en el tablero político, que obtuvieron un resultado cuando menos dudoso en términos de compromiso por parte de las cuentas de sus usuarios.

Como principal limitación de este estudio, se puede destacar que el resultado de la pugna de marcos electorales por parte de las cinco principales fuerzas políticas durante las elecciones de 2019 en España tiene difícil respuesta con las variables que se han empleado en esta investigación. En primer lugar, porque para ello se requiere conocer la finalidad de las estrategias de cibercampaña de cada partido político, algo más allá de los objetivos de la presente investigación que tan sólo describe su manifestación en redes, pero no su motivación interna. En segundo lugar, tratar de evaluar la estrategia en Facebook en función del número de interacciones recibidas en principio indicaría el acierto en las estrategias de PSOE y Unidas Podemos. Sin embargo, el alcance de las métricas de engagement debe ser interpretado cautelosamente, en tanto se han extendido estrategias automatizadas para manipular difusión y algoritmos (Arnaudo, 2017), mediante la compra de seguidores, likes o comparticiones (p. ej., Fernández, 2018; Caldarelli et al., 2019; Carrasco, 2019). El engagement manifestado en redes sociales sería así una combinación de las interacciones de usuarios reales y computerizados. Por tanto, futuras investigaciones han de inquirir, tanto cuantitativa como cualitativamente, por este tipo de cuestiones, especialmente en lo referente a la validez de las métricas sociales y a la detección de dispositivos automáticos que las alteren.

Complementariamente, se estima de interés la comparación del tipo de enmarcado propio encontrado en la campaña electoral con el que pueda realizarse fuera de ésta, abarcando así el estudio de toda la "campaña permanente" que caracteriza la comunicación política actual.

Metodológicamente, esta investigación ha mostrado la utilidad de la propuesta de Matthes y Kohring (2008), adaptada en castellano por autores como Rodelo y Muñiz (2016), para detectar y describir los marcos utilizados por los partidos políticos en redes sociales durante campaña electoral. El análisis de los marcos mediante la detección estadística de conglomerados permite mejorar tanto la fiabilidad, pues ofrece una herramienta que puede ser utilizada de un mismo modo en diferentes momentos, como la validez de la investigación de los marcos, pues emplea los elementos de enmarcado utilizados por los propios emisores partiendo de la definición académicamente más citada de frame (Entman, 1993). Es deseable que la generalización de enfoques metodológicos válidos y fiables contribuyan a superar un estado de la investigación en el que el framing deje de ser una metáfora que no pueda ser traducida directamente en preguntas de investigación (Brosius; Eps, 1995).

Se detectó correlación negativa entre los marcos más empleados por los partidos y las interacciones recibidas 


\section{Referencias}

Arnaudo, Dan (2017). "Computational propaganda in Brazil: social bots during elections". Computational propaganda research project, v. 2017, n. 8.

https://ora.ox.ac.uk/objects/uuid:e88de32c-baaa-4835-bb76-e00473457f46

Ballesteros-Herencia, Carlos A. (2017). "Siguiendo al flautista. Framing del independentismo catalán en las votaciones de 2014 y 2015". Estudios sobre el mensaje periodístico, v. 23, n. 1, pp. 307-323.

https://doi.org/10.5209/ESMP.55598

Ballesteros-Herencia, Carlos A. (2019a). “La representación digital del engagement”. Revista de comunicación, v. 18, n. 1, pp. 215-33.

https://doi.org/10.26441/RC18.1-2019-A11

Ballesteros-Herencia, Carlos A. (2019b). "El índice de engagement en redes sociales como predictor de los resultados en las elecciones generales de 2015 y 2016". IC-Revista científica de información y comunicación, n. 16, pp. 615-646. http://icjournal-ojs.org/index.php/IC-Journal/article/view/456/378

Bartolomé-Castro, Manuel; Rodríguez-Virgili, Jordi (2012). “Pugna de frames en el debate político español sobre la situación económica (2008-2011)”. Estudios sobre el mensaje periodístico, v. 18, n. 2, pp. 439-457.

https://doi.org/10.5209/rev_ESMP.2012.v18.n2.41018

Borondo, Javier; Morales, Alfredo J.; Losada, Juan-Carlos; Benito, Rosa M. (2012). "Characterizing and modeling an electoral campaign in the context of Twitter: 2011 Spanish presidential election as a case study". Chaos: An interdisciplinary journal of nonlinear science, v. 22, n. 2.

https://doi.org/10.1063/1.4729139

Borondo, Javier; Morales, Alfredo J.; Losada, Juan-Carlos; Benito, Rosa M. (2016). "Analyzing the usage of social media during Spanish presidential electoral campaigns". In: 2016 IEEE/ACM International conference on advances in social networks analysis and mining, pp. 785-792.

https://ieeexplore.ieee.org/document/7752327

Breckenridge, James N. (2000). "Validating cluster analysis: Consistent replication and symmetry". Multivariate behavioral research, v. 35, n. 2, pp. 261-285.

https://doi.org/10.1207/S15327906MBR3502_5

Brosius, Hans-Bernd; Eps, Peter (1995). "Prototyping through key events: News selection in the case of violence against aliens and asylum seekers in Germany". European journal of communication, v. 10, n. 3, pp. 391-412.

https://doi.org/10.1177/0267323195010003005

Bryant, Jennings; Miron, Dorina (2004). "Theory and research in mass communications". Journal of communication, v. 4, n. 54, pp. 662-704.

https://doi.org/10.1111/j.1460-2466.2004.tb02650.x

Caldarelli, Guido; De-Nicola, Rocco; Del-Vigna, Fabio; Petrocchi, Marinella; Saracco, Fabio (2019). "The role of bot squads in the political propaganda on Twitter". Social and information networks, v. 3, n. 81.

https://doi.org/10.1038/s42005-020-0340-4

Carrasco, Pablo-Elián (2019). El voto de los bots - Producción de apoyo político con cuentas automatizadas en \#YoVotoMM.

https://data.pezdigital.com/informes/elvotodelosbots.html

Casero-Ripollés, Andreu (2018). "Research on political information and social media: Key points and challenges for the future". El profesional de la información, v. 27, n. 5, pp. 964-974.

https://doi.org/10.3145/epi.2018.sep.01

Castells, Manuel (2009). Comunicación y poder. Madrid: Alianza. ISBN: 9788420684994

Chan-OImsted, Sylvia; Wolter, Lisa; Wang, Rang (2017). “Toward a multidimensional framework of media engagement: Conceptualizing consumer experience and connection with media content in a digital environment" (poster). In: 2017 European media management conference.

https://www.media-management.eu

CIS (2019). Estudio n. 3263. Macrobarómetro de octubre de 2019. Preelectoral elecciones generales 2019.

http://www.cis.es/cis/export/sites/default/_Archivos/Marginales/3260_3279/3263/Marginales/es3263mar_Muestra_ global.pdf

Cohaila, Edwin (2019). "Framing en el debate presidencial de las elecciones peruanas de 2016 en redes sociales". Revista mexicana de opinión pública, v. 26, pp. 33-50.

https://doi.org/10.22201/fcpys.24484911e.2019.26.61557 
Dader, José-Luis (2001). “Ciberdemocracia: el mito realizable”. Palabra clave, n. 4, pp. 35-50. https://dikaion.unisabana.edu.co/index.php/palabraclave/article/viewFile/362/503

D’Angelo, Paul (2002). "News framing as a multi-paradigmatic research program: A response to Entman". Journal of communication, n. 52, pp. 870-88.

https://doi.org/10.1111/j.1460-2466.2002

Deltell, Luis (2012). “Estrategias de comunicación política en las redes sociales durante la campaña electoral de 2011 en España: El caso de Equo". En: Jornadas de la Asociación Madrileña de Sociología.

https://eprints.ucm.es/15544

De-Vreese, Claes H. (2012). "New avenues for framing research". American behavioral scientist, v. 56, n. 3, pp. 365-375. https://doi.org/10.1177/0002764211426331

Entman, Robert M. (1993). "Framing: Toward clarification of a fractured paradigm". Journal of communication, v. 43, n. 4, pp. 51-58.

https://doi.org/10.1111/j.1460-2466.1993.tb01304.x

Entman, Robert M. (2003). "Cascading activation: Contesting the White House's frame after 9/11". Political communication, v. 20, n. 4, pp. 415-432.

https://doi.org/10.1080/10584600390244176

Fenoll, Vicente; Hassler, Joerg (2019). “¿La red de los populistas? Diferencias en la campaña electoral en Facebook de España y Alemania". IC-Revista científica de información y comunicación, n. 16, pp. 451-484.

https://idus.us.es/bitstream/handle/11441/92851/Fenoll\%20-\%20red\%20populistas.pdf

Fenoll, Vicente; Rodríguez-Ballesteros, Paula (2017). “Análisis automatizado de encuadres mediáticos. Cobertura en prensa del debate 7D 2015: el debate decisivo". El profesional de la información, v. 26, n. 4, pp. 630-640.

https://doi.org/10.3145/epi.2017.jul.07

Fernández, Montse (2018). “Métricas digitales en la era de la posverdad, ¿irecetas imposibles?”. Más poder local, n. 34, pp. 15-17.

http://maspoderlocal.es/files/articulos/metricas-digitales-posverdad-mpl34.pdf

Gamir-Ríos, José (2016). “Blogs, Facebook y Twitter en las elecciones generales de 2011. Estudio cuantitativo del uso de la web 2.0 por parte de los cabezas de lista del PP y del PSOE". Revista dígitos, n. 2, pp.101-120.

https://revistadigitos.com/index.php/digitos/article/view/53

Gerodimos, Roman; Justinussen, Jákup (2015). “Obama's 2012 Facebook campaign: Political communication in the age of the like button". Journal of information technology \& politics, v. 12, n. 2, pp. 113-132.

https://doi.org/10.1080/19331681.2014.982266

Gibson, James L.; Caldeira, Gregory A. (2009). Citizens, courts and confirmations: Positivity theory and the judgments of the American people. Princeton University Press. ISBN: 9780691139883

Gruszczynski, Michael W.; Michaels, Sarah (2012). "The evolution of elite framing following enactment of legislation". Policy sciences, v. 45, pp. 359-384.

https://doi.org/10.1007/s11077-012-9153-y

Hands, Stephen; Everitt, Brian (2010). "A Monte Carlo study of the recovery of cluster structure in binary data by hierarchical clustering techniques". Multivariate behavioral research, v. 22, n. 2, pp. 235-243.

https://doi.org/10.1207/s15327906mbr2202_6

Hanson, Gary; Haridakis, Paul-Michael; Cunningham, Audrey-Wagstaff; Sharma, Rekha; Ponder, James D. (2010). "The 2008 presidential campaign: Political cynicism in the age of Facebook, MySpace, and YouTube". Mass communication and society, v. 13, n. 5, pp. 584-607. https://doi.org/10.1080/15205436.2010.513470

Heiss, Raffael; Schmuck, Desiree; Matthes, Jörg (2019). “What drives interaction in political actors' Facebook posts? Profile and content predictors of user engagement and political actors' reactions". Information, communication \& society, v. 22, n. 10, pp. 1497-1513.

https://doi.org/10.1080/1369118X.2018.1445273

Hootsuit (2020). Digital 2020. Global digital overview.

https://wearesocial.com/digital-2020

Hothanm, Tristan (2019). Goodbye Netvizz. Netvizz, the Facebook app created by researcher Bernhard Rieder is dead. https://tristanhotham.com/2019/08/21/goodbye-netvizz 
Igartua, Juan-José (2006). Métodos cuantitativos de investigación en comunicación. Barcelona: Bosch. ISBN: 97884 97902717

Igartua, Juan-José; Muñiz, Carlos; Cheng, Lifen (2005). “La inmigración en la prensa española. Aportaciones empíricas y metodológicas desde la teoría del encuadre noticioso". Migraciones, n. 17, pp. 143-181.

https://revistas.comillas.edu/index.php/revistamigraciones/article/view/4220

Just, Sine-Nørholm; Mouton, Nico (2014). “Framing financial culture - rhetorical struggles over the meaning of "Liborgate". Journal of organizational change management, v. 27, n. 5, pp. 732-743.

https://doi.org/10.1108/JOCM-09-2014-0170

Larsson, Anders O. (2015). "Going viral? Comparing parties on social media during the 2014 Swedish election". Convergence, v. 23, n. 2, pp. 117-131.

https://doi.org/10.1177/1354856515577891

Larsson, Anders O.; Kalsnes, Bente (2014). "'Of course we are on Facebook': Use and non-use of social media among Swedish and Norwegian politicians". European journal of communication, v. 29, n. 6, pp. 653-667.

https://doi.org/10.1177/0267323114531383

López-García, Guillermo (2016). “'Nuevos' y 'viejos' liderazgos: la campaña de las elecciones generales españolas de 2015 en Twitter". Communication \& society, v. 29. n. 3, pp. 149-167.

https://doi.org/10.15581/003.29.3.sp.149-167

López-García, Guillermo; Gamir-Ríos, José-Vicente; García-Ull, Francisco-José; Llorca-Abad, Germán; Cano-Orón, Lorena; González-Esteban, José-Luis (2015) “El debate sobre Europa en Twitter. Discursos y estrategias de los candidatos de las elecciones al Parlamento Europeo de 2014 en España”. Revista de estudios políticos, n. 170, pp. 213-246.

https://doi.org/10.18042/cepc/rep.170.07

López-Meri, Amparo; Marcos-García, Silvia; Casero-Ripollés, Andreu (2017). "What do politicians do on Twitter? Functions and communication strategies in the Spanish electoral campaign of 2016". El profesional de la información, v. 26, n. 5, pp. 795-804.

https://doi.org/10.3145/epi.2017.sep.02

López-Meri, Amparo; Marcos-García, Silvia; Casero-Ripollés, Andreu (2020). “Estrategias comunicativas en Facebook: personalización y construcción de comunidad en las elecciones de 2016 en España”. Doxa comunicación, n. 30.

https://doi.org/10.31921/doxacom.n30a12

López-Rabadán, Pablo (2010). “Nuevas vías para el estudio del framing periodístico. La noción de estrategia de encuadre". Estudios sobre el mensaje periodístico, n. 16, pp. 235-258.

https://revistas.ucm.es/index.php/ESMP/article/view/ESMP1010110235A

Macnamara, Jim; Sakinofsky, Phyllis; Beattie, Jenni (2012). "E-electoral engagement: How governments use social media to engage voters". Australian Journal of political science, v. 47, n 4, pp. 623-639.

https://doi.org/10.1080/10361146.2012.731491

Matthes, Jörg; Kohring, Matthias (2008). "The content analysis of media frames: Toward improving reliability and validity". Journal of communication, v. 58, n. 2, pp. 258-279.

https://doi.org/10.1111/j.1460-2466.2008.00384.x

Matthes, Jörg (2009). "What's in a frame? A content analysis of media framing studies in the world's leading communication journals, 1990-2005". Journalism \& mass communication quarterly, v. 86, n. 2, pp. 349-367.

https://doi.org/10.1177/107769900908600206

Miller, M. Mark; Riechert, Bonnie-Parnell (2001). "The spiral of opportunity and frame resonance: mapping the issue cycle in news and public dicourse". In: Reese, Stephen; Gandy, Oscar; Grant, August. Framing public life: Perspectives on media and our understanding of the social world. New Jersey: Routledge, pp. 107-121. ISBN: 141060568 X

Muñiz, Carlos (2015). "La política como debate temático o estratégico. Framing de la campaña electoral mexicana de 2012 en la prensa digital". Comunicación y sociedad, n. 23, pp. 67-95.

http://www.scielo.org.mx/pdf/comso/n23/n23a4.pdf

Muñiz, Carlos; Ballesteros, Carlos (2016). Propuesta metodológica para el análisis de la cibercampaña electoral. En: Dader, José-Luis; Campos, Eva. La cibercampaña en Castilla y León: elecciones autonómicas 2015. Valladolid: Universidad de Valladolid, pp. 39-52. ISBN: 9788484488873

Niciporuc, Tudor (2014). "Comparative analysis of the engagement rate on Facebook and Google Plus social networks". In: International academic conferences, pp. 334-339.

https://www.iises.net/proceedings/14th-international-academic-conference-malta/table-of-content?cid=9\&iid=56\&rid=2287 
Ortiz, Selena E. (2013). Identifying alternative frames and values to increase public support for health policies that target obesity.

https://escholarship.org/uc/item/2339r991

Park, Young-Hwan (2010). Competing issue frames and attitude consistency. https://ir.ua.edu/bitstream/handle/123456789/929/file_1.pdf

Peytibi, Xavier; Rodríguez, José A.; Gutiérrez-Rubí, Antoni (2008). “L'experiència de les eleccions generals 2008”. Revista de internet, derecho y política, n. 7, pp. 26-37.

https://www.raco.cat/index.php/IDP/article/view/129985

https://doi.org/10.7238/idp.v0i7.495

Piñeiro-Naval, Valeriano; Mangana, Rafael (2019). "La presencia del framing en los artículos publicados en revistas hispanoamericanas de comunicación indexadas en Scopus". Palabra clave, v. 22, n. 1, pp. 117-142.

https://doi.org/10.5294/pacla.2019.22.1.6

Pletikosa-Cvijikj, Irena; Michahelles, Florian (2013). "Online engagement factors on Facebook brand pages". Social network analysis and mining, v. 3, n. 4, pp. 843-861.

https://doi.org/10.1007/s13278-013-0098-8

Riffe, Daniel; Lacy, Stephen; Watson, Brendan R.; Fico, Frederick (2019). Analyzing media messages. Using quantitative content analysis in research (4 ${ }^{\text {th }}$ ed.). New York: Routledge. ISBN: 9781138613980

Rodelo, Frida; Muñiz, Carlos (2016). “Uso del análisis de conglomerados para la detección de encuadres en el tratamiento periodístico de la Iniciativa Mérida". Comunicación y sociedad, n. 27, pp. 53-77.

http://eprints.uanl.mx/id/eprint/11623

Rodríguez-Virgili, Jordi; Sádaba-Garraza, Teresa; La-Porte, Teresa (2008). "La teoría del framing en la investigación en comunicación política”. En: Canel, María-José; García-Gurrionero, Mario. Estudios de comunicación política: libro del año 2008. Madrid: Asociación Comunicación Política, pp. 15-30. ISBN: 8495903180

Sádaba-Garraza, Teresa; Rodríguez-Virgili, Jordi; Bartolomé-Castro, Manuel (2012). "Propuesta de sistematización de la teoría del framing para el estudio de la comunicación política”. Observatorio (OBS*) journal, v. 6, n. 2, pp. 109-126. http://obs.obercom.pt/index.php/obs/article/viewFile/540/564

Sampietro, Agnese; Valera-Ordaz, Lidia (2015). "Emotional politics on Facebook. An exploratory study of Podemos' discourse during the European election campaign 2014". Recerca, n. 17, pp. 61-83.

https://doi.org/10.6035/Recerca.2015.17.4

Scheufele, Dietram A. (1999). "Framing as a theory of media effects". Journal of communication, v. 49, n. 1, pp. $103-122$. https://doi.org/10.1111/j.1460-2466.1999.tb02784.x

Segado-Boj, Francisco (2020). "Research on social media and journalism (2003-2017): a bibliometric and content review". Transinformação, v. 32

https://doi.org/10.1590/1678-9865202032e180096

Slothuus, Rune; De-Vreese, Claes H. (2010). "Political parties, motivated reasoning, and issue framing effects". The journal of politics, v. 72, n. 3, pp. 630-645.

https://doi.org/10.1017/S002238161000006X

Sobaci, Mehmet; Hatipoğlu, Ibrahim (2017). "Measuring the engagement level of political parties with public on Facebook: The case of Turkey". In: $7^{\text {th }}$ International conference for e-democracy and open government, pp. 209-216. https://doi.org/10.1109/CeDEM.2017.15

Suau-Gomila, Guillem (2020). “Microblogging electoral: la estrategia comunicativa de Podemos y Ciudadanos en Twitter en las campañas electorales del 20D y el 26J". Prisma social, n. 28, pp. 103-126.

https://revistaprismasocial.es/article/view/3389

Suau-Gomila, Guillem; Pont-Sorribes, Carles (2019). “Microblogging electoral e información política. La viralidad el mensaje político en Twitter". Más poder local, n. 38, pp. 54-64.

https://dialnet.unirioja.es/servlet/articulo?codigo $=7023492$

http://maspoderlocal.es/files/articulos/viralidad-mensaje-twitter-partidos-mp/38.pdf

Torres-Nabel, Luis-César (2014). “El poder de las redes sociales: la 'mano invisible' del framing noticioso. El caso de \#LadyProfeco". Icono14, v. 12, n. 2, pp. 318-337.

https://doi.org/10.7195/ri14.v12i2.625

Triantafillidou, Amalia; Lappas, Georgios; Yannas, Prodromos; Kleftodimos, Alexandros (2015). "Facebook engagement and Greek local municipal governments". In: Conference for e-democracy and open governement, pp. 39-52. 
The Social Media Family (2020). Informe sobre el uso de las redes sociales.

https://thesocialmediafamily.com/informe-redes-sociales

Túñez, Miguel; Sixto, José (2011). “Redes sociales, política y compromiso 2.0: La comunicación de los diputados españoles en Facebook". Revista latina de comunicación social, n. 66, pp. 210-246.

https://doi.org/10.4185/RLCS-66-2011-930-210-246

Vaccari, Cristian (2010). "'Technology is a commodity': the internet in the 2008 United States presidential election". Journal of information technology \& politics, v. 7, n. 4, pp. 318-339.

https://doi.org/10.1080/19331681003656664

Valenzuela, Sebastián; Piña, Martina; Ramírez, Josefina (2017). "Behavioral effects of framing on social media users: How conflict, economic, human interest, and morality frames drive news sharing". Journal of communication, v. 67, n. 5, pp. 803-826.

https://doi.org/10.1111/jcom.12325

Valera-Ordaz, Lidia (2016). “El sesgo mediocéntrico del framing en España: una revisión crítica de la aplicación de la teoría del encuadre en los estudios de comunicación". ZER, v. 21, n. 41, pp. 13-31.

https://doi.org/10.1387/zer.16404

Valera-Ordaz, Lidia; López-García, Guillermo (2014). “Agenda and frames in the websites of the People's Party (PP) and the Spanish Socialist Workers' Party (PSOE) in the 2011 cyber campaign". Revista latina de comunicación social, n. 69, pp. 41-66.

http://www.revistalatinacs.org/069/paper/1000_Valencia/03_Valeraen.html

Vallespín, Fernando (2011). "Redes sociales y democracia: ¿un cambio cualitativo?". Telos. Cuadernos de comunicación e innovación, n. 89, pp. 57-60.

https://bit.ly/2K3Hms1

Vliegenthart, Rens; Van-Zoonen, Liesbet (2011). "Power to the frame: Bringing sociology back to frame analysis". European journal of communication, v. 26, n. 2, pp. 101-115.

https://doi.org/10.1177/0267323111404838

Voltolini, Benedetta (2013). Lobbying in EU foreign policy-making towards the Israeli-Palestinian conflict: Exploring the potential of a constructivist perspective.

http://etheses.Ise.ac.uk/751/1/Voltolini_Lobbying_EU_foreign_policy-making.pdf

Weaver, David H. (2007). "Thoughts on agenda setting, framing, and priming". Journal of communication, v. 57, n. 1, pp. 142-147.

https://doi.org/10.1111/j.1460-2466.2006.00333.x

Williams, Christine B.; Gulati, Girish J. (2007). "Social networks in political campaigns: Facebook and the 2006 midterm elections". In: Annual meeting of the American Political Science Association, pp. 49-62.

Williams, Christine B.; Gulati, Girish J. (2013). "Social networks in political campaigns: Facebook and the congressional elections of 2006 and 2008". New media \& society, v. 15, n. 1, pp. 52-71.

https://doi.org/10.1177/1461444812457332 